\title{
Prospective assessment of severe hypoglycaemia in diabetic children and adolescents with impaired and normal awareness of hypoglycaemia
}

\author{
L. Barkai, I. Vámosi, K. Lukács \\ II. Department of Paediatrics, Postgraduate Medical Faculty, Imre Haynal University of Health Sciences, \\ Borsod County Teaching Hospital, Miskolc, Hungary
}

\begin{abstract}
Summary To establish whether impaired hypoglycaemic awareness is associated with increased rate of severe hypoglycaemia and to assess clinical predictors of severe episodes without warning symptoms a prospective study of 130 insulin-dependent diabetic children and adolescents was undertaken for 1 year. Using a structured questionnaire, 48 patients reported impaired awareness and 82 reported normal awareness of hypoglycaemia at baseline of the study. The two groups did not differ regarding clinical and metabolic characteristics. Episodes of severe hypoglycaemia were recorded for 1 year. The rate of severe hypoglycaemia was higher in the group with impaired awareness than in the group with normal awareness $(p<0.0001)$. Of the severe hypoglycaemic episodes, $34.0 \%$ developed without warning symptoms. Patients with impaired awareness experienced more severe episodes without warning symptoms than those with normal awareness $(p=0.0054)$. Severe hypoglycaemia occurred more frequently in patients with impaired awareness aged 6 years and less
\end{abstract}

$(p=0.0041)$ than in older counterparts. Impaired awareness reported at baseline [adjusted odds ratio (OR): $5.8 ; p=0.0021]$, age 6 years or less (3.4; $p=0.0121)$, previous severe episode $(4.8 ; p=0.0043)$ and more than $5 \%$ of home blood glucose readings $3.3 \mathrm{mmol} / \mathrm{l}$ or less in the preceding month (4.2; $p=0.0211$ ) proved to be independently predictive of severe hypoglycaemic events without warning symptoms. In conclusion, impaired hypoglycaemic awareness is associated with an increased rate of severe hypoglycaemia in diabetic children and adolescents. One third of severe episodes developed without warning symptoms. Impaired awareness, young age and recent biochemical or severe hypoglycaemias are independent risk factors for such episodes. Avoidance of hypoglycaemia should be a priority in preschool children with diabetes. [Diabetologia (1998) 41: 898-903]

Keywords Hypoglycaemia, Type I diabetes, hypoglycaemic awareness, children.
The goal of the treatment for Type I (insulin-dependent) diabetes mellitus is to achieve near-normal glycaemia as early as possible in as many patients as is safely possible. Hypoglycaemia is the most common and dangerous side effect of insulin treatment and the prevalence of severe episodes remains a major

Received: 15 December 1997 and in revised form: 5 March 1998

Corresponding author: Dr. L. Barkai, II. Department of Paediatrics, Postgraduate Medical Faculty, Imre Haynal University of Health Sciences, Borsod County Teaching Hospital, H-3501 Miskolc, Szentpéteri kapu 76, Hungary obstacle in attempts to prevent long-term diabetic complications with intensive insulin therapy. The Diabetes Control and Complications Trial has recently shown that intensification of insulin therapy increases threefold the risk of severe hypoglycaemia in adolescent and adult Type I patients [1,2]. Undesirable consequences of hypoglycaemia are particularly important in children, and primarily in young children, because severe hypoglycaemic events may impair normal brain development and neuropsychologic functioning $[3,4,5,6]$. The perception of symptoms of hypoglycaemia (hypoglycaemia awareness) is the first line of defence mechanisms against blood glucose decline: it alerts the patient to the early development of 
a low blood glucose and so initiates self treatment. It has been shown that about $20-35 \%$ of insulin-treated patients, at least occasionally, lose ability of the awareness of hypoglycaemic symptoms $[7,8,9,10]$. Therefore, impaired awareness of hypoglycaemia has important clinical impact and interferes with the aim of normoglycaemic control to prevent long-term complications of Type I diabetes. The effect of impaired awareness of hypoglycaemia on the frequency and severity of hypoglycaemic episodes in children and adolescents with diabetes is not known. The aims of the present study were to investigate the relationship between severe episodes of hypoglycaemia and impaired hypoglycaemic awareness in children and adolescents with Type I diabetes studied prospectively and to establish clinical predictors of severe hypoglycaemic events without warning symptoms.

\section{Subjects and methods}

Patients. Patients having Type I diabetes for more than 1 year, not older than 18 years and who agreed to participate in a close follow up for 1 year were included in this study. Patients with autonomic neuropathy (assessed by cardiovascular tests) were excluded (11) but no other exclusion criteria were used. The prospective study from February 1996 to March 1997 was completed by 130 patients (aged 3 to 17 years). They represented $76 \%$ of the diabetic children seen in our clinic during the study period. All patients were treated with combinations of short and intermediate acting human insulin injected two to five times daily. Pre-school children were treated mainly with a twice daily insulin regimen. The majority of older children, especially pubertal patients, were treated using a multiple insulin injection regimen. Patients and parents had undergone standard diabetes education, including the recognition and treatment of hypoglycaemia. All parents and children were encouraged to achieve optimal metabolic control by the diabetes care team. Parents and patients routinely adjusted insulin according to home glucose levels to allow for exercise patterns and food intake. All subjects and their parents gave their informed consent, and the study was approved by the regional ethics committee.

Classification of awareness of hypoglycaemia. At baseline of the study, patients and parents were interviewed using a structured questionnaire about hypoglycaemic episodes during the preceding year, how frequently these had occurred, which symptoms were usually experienced and whether they were aware of the onset of symptoms of hypoglycaemia. The patients were not informed of a specific interest in hypoglycaemia unawareness. Patients were categorised into two groups according to their state of awareness of the onset of hypoglycaemia. Those patients who were always aware of the onset of their hypoglycaemic episodes were classified as having normal awareness. Those who were aware of some episodes but not others or who were never able to recognise any episodes of hypoglycaemia were classified as having impaired awareness (Table 1). Hypoglycaemia awareness was defined by clinical history criteria rather than by the response to experimental hypoglycaemia induced in a laboratory setting, as this was considered to be more relevant to the hypoglycaemia experienced during daily life and takes into account the patient's subjective reality. To validate the questionnaire, the accuracy of allocation of patients on historical grounds to each of the groups
Table 1. Baseline characteristics of children and adolescents with Type I diabetes with impaired and normal awareness of hypoglycaemia. Means \pm SD or number (\%)

\begin{tabular}{|c|c|c|c|}
\hline & $\begin{array}{l}\text { Impaired } \\
\text { awareness }\end{array}$ & $\begin{array}{l}\text { Normal } \\
\text { awareness }\end{array}$ & $p$ value \\
\hline$n$ & 48 & 82 & \\
\hline Male/female & $26 / 22$ & $42 / 40$ & NS \\
\hline Age (years) & $12.5 \pm 4.0$ & $13.1 \pm 3.2$ & NS \\
\hline Patients aged 6 years or less & $7(14.6)$ & $11(13.4)$ & NS \\
\hline Diabetes duration (years) & $4.6 \pm 3.3$ & $4.7 \pm 3.4$ & NS \\
\hline No. insulin injections & $3.5 \pm 0.8$ & $3.7 \pm 0.7$ & NS \\
\hline $\begin{array}{l}\text { Dose of insulin } \\
\left(\mathrm{U} \cdot \mathrm{kg}^{-1} \cdot \mathrm{day}^{-1}\right)\end{array}$ & $0.81 \pm 0.1$ & $0.86 \pm 0.3$ & NS \\
\hline $\mathrm{HbA}_{1 \mathrm{c}}$ since diabetes onset (\%) & $8.6 \pm 2.1$ & $8.6 \pm 1.9$ & NS \\
\hline BMI $\left(\mathrm{kg} / \mathrm{m}^{2}\right)$ & $20.2 \pm 4.1$ & $20.4 \pm 3.8$ & NS \\
\hline $\begin{array}{l}\text { Awareness on linear analogue } \\
\text { scale, median (range) }\end{array}$ & $1.8 \pm 0.3$ & $4.9 \pm 1.4$ & $<0.0001$ \\
\hline $\begin{array}{l}\text { History of hypoglycaemia } \\
1 \text { or more events per month } \\
\text { less than } 1 \text { event per month }\end{array}$ & $\begin{array}{l}18(37.5) \\
30(62.5)\end{array}$ & $\begin{array}{l}32(39.0) \\
50(61.0)\end{array}$ & $\begin{array}{l}\text { NS } \\
\text { NS }\end{array}$ \\
\hline
\end{tabular}

was assessed by a linear analogue scale of 1 to $7(1=$ never aware and $7=$ always aware of the onset of hypoglycaemia). The group of patients that reported impaired awareness of hypoglycaemia estimated their awareness on the linear analogue scale significantly lower than the group of patients with normal awareness. There were no significant differences between the two groups regarding clinical characteristics (Table 1).

Protocol. Data were collected prospectively over a 1-year period. Children and parents were asked to record any hypoglycaemic episodes when they occurred, along with details of the event in a standardised data collection form. Patients were requested to come to the clinic or contact the physician immediately in the event of severe hypoglycaemia. Patients were seen in clinic every 6 to 12 weeks and over the 1 -year study, all patients attended a minimum of four visits per year. At each clinic attendance, a detailed history was obtained by the physician about any episode of hypoglycaemia since the previous visit. The patients were questioned about warning symptoms and signs and the circumstances of the event. The mode of treatment was also recorded. In addition, the number of total blood glucose determinations and results with a blood glucose level $3.3 \mathrm{mmol} / 1$ or less (biochemical hypoglycaemia) were also counted in the daily diabetes notebooks. Patients with impaired awareness of hypoglycaemia were compared with the group of patients with normal hypoglycaemia awareness. Comparisons between the groups were made by clinical and biochemical characteristics and by the occurrence of hypoglycaemic episodes during the study period. Furthermore, possible risk factors for severe episodes without warning symptoms were analysed.

Definition of hypoglycaemia. A hypoglycaemic event was defined as an episode which was accompanied by typical common symptoms of hypoglycaemia and which was corrected by oral carbohydrate, parenteral glucose or glucagon therapy, irrespective of whether hypoglycaemia had been demonstrated by blood glucose measurement. Severe hypoglycaemia was defined as any event requiring the assistance of another person for treatment; all other episodes were considered to be mild. Episodes of asymptomatic blood glucose level $3.3 \mathrm{mmol} / \mathrm{l}$ or less, identified by the random blood glucose monitoring dia- 
ries, were not included in the total number of episodes of mild hypoglycaemia. For younger children the definition of severe hypoglycaemia is troublesome, as all symptomatic episodes need parental assistance and can be designated as severe events. Therefore, events resulting in coma or seizure were counted separately as a subset of severe events.

Laboratory measurements. Long-term metabolic control was estimated by mean glycated haemoglobin $\left(\mathrm{HbA}_{1 \mathrm{c}}\right)$ measured 3 monthly. This was measured by an ion capture assay (IMx Glycated Haemoglobin Assay, Abbott Laboratories, Chicago, USA), with a non-diabetic range of 4.4 to $6.4 \%$.

Statistical analysis. Clinical characteristics of study groups are given as means \pm SD or number (\%). Student's $t$-test was used for unpaired samples. Data that were not normally distributed were analysed using Wilcoxon rank sum test. Fisher's exact test was used to assess association between categorical variables. Multiple logistic regression analysis was applied for discrete binary variables and odds ratios (OR) with $95 \%$ confidence intervals $(95 \% \mathrm{CI})$ were calculated. $P$ value less than $5 \%$ was considered statistically significant.

\section{Results}

Clinical characteristics of study groups with impaired and normal awareness are shown in Tables 1 and 2 . There were no significant differences between the two groups regarding treatment modalities, pattern of home blood glucose monitoring and level of glycaemia either at baseline or during the follow-up period. Of the patients $16(33.3 \%)$ in the impaired awareness group as compared with $12(14.6 \%)$ in the normal awareness group experienced at least one episode of severe hypoglycaemia in 1 year $(p=0.0156)$. Five $(10.4 \%)$ patients in the group with impaired awareness and one $(1.2 \%)$ patient in the group with normal awareness had one or more episodes of coma or seizure in 1 year $(p=0.0256)$.

During the 1-year study, a total of 50 severe hypoglycaemic episodes and 8 episodes of coma or seizure were recorded. Thus, the overall incidence of all severe episodes was 38.5 per 100 patient-years and of coma or seizure was 6.2 per 100 patient-years. As shown in Figure 1, the rate of severe hypoglycaemia was significantly higher in the group with impaired awareness than in the group with normal awareness: 30 and 20 episodes were registered in the two groups, (62.5 vs 24.4 episodes per 100 patient-years, $p<0.0001)$. Similarly, seven episodes compared with one episode of a coma or seizure were observed in the groups with impaired and normal awareness, respectively (14.6 vs 1.2 episodes per 100 patient-years, $p=0.0020)$. The frequency of mild hypoglycaemic episodes was similar in the two study groups (402.1 vs 390.2 episodes per 100 patient-years, NS). Overall, the majority of severe hypoglycaemic episodes occurred during awake periods and a similar proportion of episodes occurred in both groups during sleeping periods $(5 / 30$ vs $3 / 20$, NS). Over the 1 -year period,

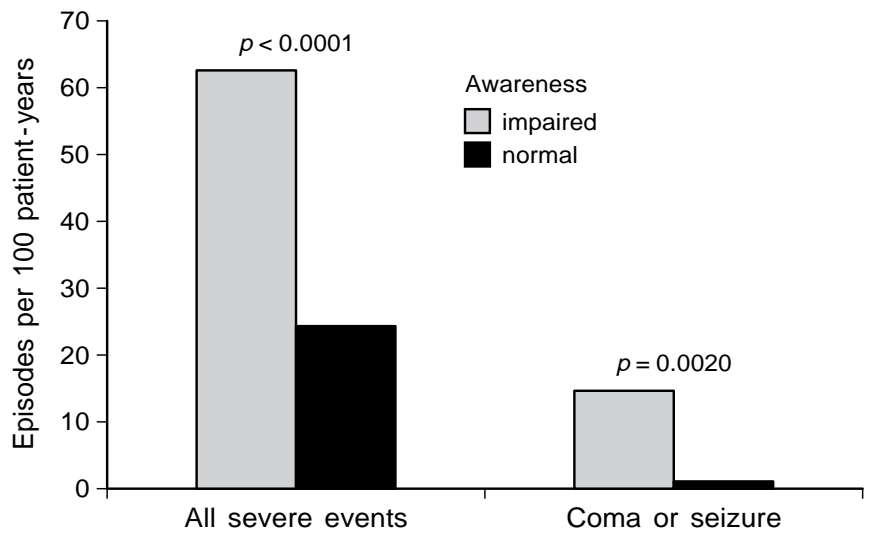

Fig. 1. Rates of severe hypoglycaemia in children and adolescents with Type I diabetes according to state of hypoglycaemic awareness

Table 2. Characteristics of children and adolescents with Type I diabetes with impaired and normal awareness of hypoglycaemia during 1 year of follow-up. Means \pm SD

\begin{tabular}{lccc}
\hline & $\begin{array}{l}\text { Impaired aware- } \\
\text { ness }(n=48)\end{array}$ & $\begin{array}{l}\text { Normal aware- } \\
\text { ness }(n=82)\end{array}$ & \\
\hline $\begin{array}{l}\text { No. insulin injections } \\
\begin{array}{l}\text { Dose of insulin } \\
\left(\mathrm{U} \cdot \mathrm{kg}^{-1} \cdot \text { day }^{-1}\right)\end{array}\end{array}$ & $3.5 \pm 0.8$ & $3.7 \pm 0.7$ & $\mathrm{NS}$ \\
$\begin{array}{l}\text { No. daily blood glucose } \\
\text { measurements }\end{array}$ & $0.82 \pm 0.2$ & $0.87 \pm 0.3$ & $\mathrm{NS}$ \\
$\begin{array}{l}\mathrm{HbA} \text { 1c } \%) \text { over 1 year } \\
\% \text { blood glucose }\end{array}$ & $8.6 \pm 2.3$ & $8.7 \pm 2.1$ & $\mathrm{NS}$ \\
$\begin{array}{l}3.3 \text { mmol/1 or less } \\
\text { during 1 year }\end{array}$ & $4.2 \pm 3.9$ & $4.6 \pm 3.5$ & $\mathrm{NS}$ \\
\hline
\end{tabular}

17 of $50(34.0 \%)$ severe hypoglycaemic episodes developed without warning symptoms or signs. Patients with impaired awareness experienced more severe episodes without warning symptoms than those with normal awareness $(15 / 30$ vs $2 / 20, p=0.0054)$. In the group with impaired awareness, young diabetic children ( $\leq 6$ years) experienced more episodes of severe hypoglycaemia (114.3 vs 53.7 episodes per 100 patient-years, $p=0.0041)$ and coma or seizure (57.1 vs 7.3 episodes per 100 patient-years, $p=0.0003$ ) than older patients (Fig. 2 and 3).

When the blood glucose control prior to the severe episodes was analysed (Table 3 ), a significantly higher percentage of episodes with values of $3.3 \mathrm{mmol} / 1$ or less was observed in the preceding month without warning symptoms compared with those that occurred with warning symptoms. Mean blood glucose concentration of the preceding month and the closest $\mathrm{HbA}_{1 \mathrm{c}}$ did not differ significantly. Using multiple logistic regression analysis, impaired awareness of hypoglycaemia reported at baseline, age 6 years or less, a severe episode within one month prior to the event and more than $5 \%$ of home blood glucose readings $3.3 \mathrm{mmol} / \mathrm{l}$ or less in the preceding month proved to 


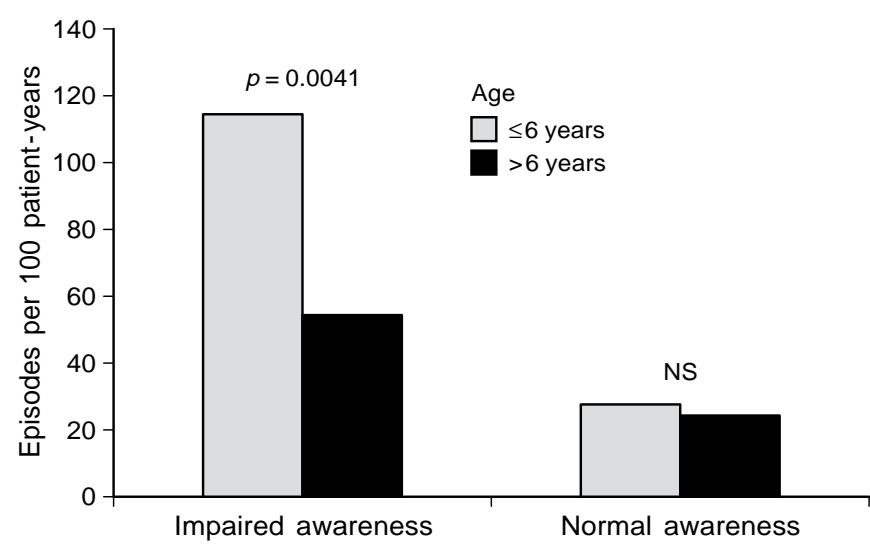

Fig. 2. Rates of all severe hypoglycaemia in children and adolescents with Type I diabetes with impaired and normal hypoglycaemic awareness for two age groups

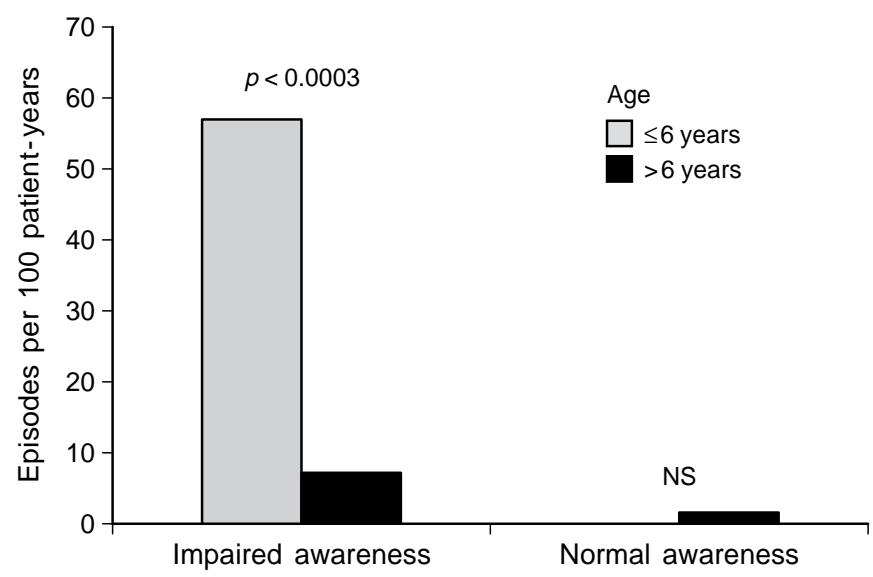

Fig.3. Rates of coma or seizure in children and adolescents with Type I diabetes with impaired and normal hypoglycaemic awareness for two age groups

be independently predictive to severe hypoglycaemic events without warning symptoms when the latter was used as a dependent variable in the model (Table 4). None of the other baseline characteristics (age, sex, $\mathrm{HbA}_{1 \mathrm{c}}$ since diabetes onset, number of insulin injections, dose of insulin, history of hypoglycaemia), the closest $\mathrm{HbA}_{1 \mathrm{c}}$, mean blood glucose level in the preceding month or time of event were associated with the absence of warning symptoms in this multivariate analysis.

\section{Discussion}

In our prospective study the incidence of severe hypoglycaemic episodes, defined as any event requiring external assistance with treatment, was 38.5 per 100 patient-years. This is lower than the frequency observed in adolescents treated intensively (85.7 per 100 patient-years) but higher than the rate reported in those treated conventionally $(27.8$ per 100 patient-
Table 3. Preceding blood glucose control of severe hypoglycaemic episodes according to the presence or absence of warning symptoms. Means \pm SD

\begin{tabular}{llll}
\hline & $\begin{array}{l}\text { Episodes } \\
\text { without } \\
\text { warning } \\
\text { symptoms } \\
(n=17)\end{array}$ & $\begin{array}{l}\text { Episodes } \\
\text { with warning } \\
\text { symptoms } \\
(n=33)\end{array}$ & $p$ value \\
& $8.4 \pm 2.2$ & $8.3 \pm 2.3$ & NS \\
\hline $\begin{array}{l}\text { Closest HbA } 1 \mathrm{c}(\%) \\
\text { Mean blood glucose in } \\
\text { preceding month (mmol/l) }\end{array}$ & $8.7 \pm 3.8$ & $8.8 \pm 3.1$ & NS \\
$\begin{array}{l}\text { No. daily blood glucose } \\
\text { measurements }\end{array}$ & $2.3 \pm 0.6$ & $2.2 \pm 0.8$ & NS \\
$\begin{array}{l}\text { Percent blood glucose } \\
\begin{array}{l}3.3 \text { mmol/l or less in } \\
\text { preceding month }\end{array}\end{array}$ & $7.4 \pm 4.5$ & $4.4 \pm 3.8$ & 0.028 \\
\hline
\end{tabular}

Table 4. Risk factors for severe hypoglycaemic episodes without warning symptoms

\begin{tabular}{llll}
\hline & $\begin{array}{l}\text { Adjusted } \\
\text { OR }\end{array}$ & 95\% CI & $p$ value \\
\hline $\begin{array}{llll}\text { Impaired awareness } \\
\text { at baseline }\end{array}$ & 5.8 & $2.3-13.2$ & 0.0021 \\
$\begin{array}{l}\text { Age 6 years or less } \\
\begin{array}{l}\text { Severe hypoglycaemic episode } \\
\text { in preceding month }\end{array}\end{array}$ & 3.4 & $1.3-5.8$ & 0.0121 \\
$\begin{array}{l}>\text { 5\% of home blood glucose } \\
\text { readings 3.3 mmol/1 or less }\end{array}$ & 4.8 & $2.2-8.4$ & 0.0043 \\
\hline
\end{tabular}

years) in the DCCT study [2]. The incidence of 6.2 per 100 patient-years for episodes of coma or seizure in our study is lower than that reported by the DCCT study which was 26.7 and 9.7 per 100 patientyears in the intensive and conventional groups, respectively [2]. These differences could be due to differences in age and treatment modalities but comparison is difficult as patient selection was also different. In a recent prospective study from Western Australia, the rate of all episodes of significant hypoglycaemia in diabetic children and adolescents, defined as events requiring the assistance from another person for treatment, was 17.9 per 100 patient-years and the rate of episodes of coma or convulsion was 4.8 per 100 patient-years [12]. These rates are lower than corresponding rates observed in our study, which could be due to the less extensive use of multiple insulin injection regimen in the Australian study. There is no paediatric data available with which to compare our present findings of the relationship between hypoglycaemia awareness and rate of severe hypoglycaemia. In adult Type I diabetic patients, Gold et al. [13] demonstrated that impaired hypoglycaemia awareness predisposes to a sixfold increase in the frequency of severe hypoglycaemia defined as any episode requiring external assistance. It is difficult, however, to extrapolate the findings of studies on adult patients to 
younger subjects because of the differences in treatment regimens, in behaviour and in responses to hypoglycaemia between adults and children [14, 15, 16]. In our study, the rate of all severe hypoglycaemia was three times higher in patients with impaired awareness than in those with normal awareness. When episodes with coma or seizure were analysed separately, impaired awareness was associated with a 15 -fold increase in the rate. Therefore, our data indicate that children and adolescents with diabetes and impaired awareness are at an extreme risk of the most severe hypoglycaemic attacks.

The diabetic patient's best defence against hypoglycaemia severe enough to cause temporary loss of cognitive function, confusion, and coma is subjective awareness of a falling blood glucose concentration at a time when appropriate remedial action can be taken. Hypoglycaemia without warning symptoms has been known for a long time [17]. Impaired awareness of hypoglycaemia affects a considerable proportion of patients with Type I diabetes [9] and is a dangerous complication which limits the use of intensified insulin therapy to reduce chronic diabetic complications. The cause of impaired awareness is not clear, although it seems that it is multifactorial in origin [18]. The major risk factors for the phenomenon are longer duration of diabetes, a history of recurrent severe hypoglycaemia and intensive diabetes management $[9,19,20]$. Some data indicate that autonomic neuropathy could be one of the causes [21, 22, 23], but this may not be the whole explanation. Additional potential mechanisms include decreased responsiveness to autonomic activation and decreased perception of both autonomic and neuroglycopenic symptoms [24, 25]. Recent attention has focused on the role of the central nervous system glucoregulatory mechanisms [26, 27]. The major defect is a lowering of the glucose level at which the various responses to hypoglycaemia, including warning autonomic symptoms, begin [28]. This maladaptation of the glucoregulatory centre can be the result of enhanced brain glucose uptake induced by antecedent hypoglycaemia or tight glycaemic control [29]. In our present study, recent episodes of severe hypoglycaemia and frequent biochemical hypoglycaemias prior to the event were independent risk factors for the development of severe episodes without warning symptoms which support the hypothesis that previous hypoglycaemic experience can contribute to a shift of the hypoglycaemic threshold towards lower blood glucose levels. Recent studies show that responses of hypoglycaemia in subjects with impaired awareness can be restored by adjusting treatment regimens with the aim of avoiding all episodes of even mild hypoglycaemia in daily life [30,31]. Whether the change in target blood glucose level or avoiding home glucose levels of $3.3 \mathrm{mmol} / \mathrm{l}$ or less would be successful in preventing subsequent hypoglycaemic events without warning symptoms in children and adolescents is not known at present and further studies are necessary to answer this question.

Severe hypoglycaemia, in which blood glucose concentrations fall so low that cognitive function is impaired, is a dangerous complication of insulin use affecting many children with Type I diabetes $[3,32]$. A severe episode of hypoglycaemia is generated by a series of complex biological, psychological, and behavioural processes [33]. Although, studies on the effect of recurrent episodes of hypoglycaemia on cortical function in adult subjects are inconclusive [1, 34], the finding that younger diabetic children (aged $\leq 6$ years) with impaired awareness have a substantially higher rate of severe hypoglycaemia than older counterparts is of concern, since this age group may be more susceptible to the adverse effects of neuroglycopenia $[3,4,5,6]$. On the other hand, young age proved to be an independent predictor for a severe episode without warning symptoms. A very recent prospective study on a large cohort of children and adolescents with Type I diabetes indicates that younger children are generally at increased risk of severe hypoglycaemia [12]. In addition, Beregszászi et al. [35] demonstrated that younger age is an independent risk factor for nocturnal hypoglycaemia in diabetic children. In children with diabetes, neuroglycopenic symptoms cosegregate with autonomic symptoms and the children may not experience or be able to express autonomic symptoms to the same degree as adults [16]. Although, it is known that very loose metabolic control has deleterious effects on complications and can impair linear growth, the above data underline the concept that tight control should be undertaken with extreme caution in young children with diabetes $[36,37]$.

In conclusion, impairment in hypoglycaemic symptom awareness is a frequent phenomenon in children and adolescents with Type I diabetes: one third of severe episodes develop without warning symptoms and signs. Loss of awareness of hypoglycaemia promotes susceptibility to the most severe and damaging episodes of neuroglycopenia in children and adolescents. Impaired awareness reported, young age, recent biochemical and severe hypoglycaemias are independent risk factors for severe episodes without warning symptoms and signs. Thus, more caution is needed in setting target blood glucose control in pre-school children with diabetes and avoidance of hypoglycaemia should be a priority in this age group.

\section{References}

1. Diabetes Control and Complications Research Group (1993) The effect of intensive treatment of diabetes on the development and progression of long-term complications in insulin-dependent diabetes mellitus. N Engl J Med 329: 977-986

2. Diabetes Control and Complications Research Group (1994) Effect of intensive diabetes treatment on the devel- 
opment and progression of long-term complications in adolescents with insulin dependent diabetes mellitus: Diabetes Control and Complications Trial. J Pediatr 125: 177-188

3. Ryan C, Vega A, Drash A (1985) Cognitive deficits in adolescents who developed diabetes early in life. Pediatrics 75 : 921-927

4. Rovet JF, Ehrlich RM, Hoppe M (1987) Intellectual deficits associated with early onset of insulin-dependent diabetes mellitus in children. Diabetes Care 10: 510-515

5. Soltész Gy, Acsádi G (1989) Association between diabetes, severe hypoglycaemia, and electroencephalographic abnormalities. Arch Dis Child 64: 992-996

6. Reich JN, Kaspar JC, Puczynski MS, Cleland JW, Dell'angela K, Emanuele MA (1990) Effect of a hypoglycaemic episode on neuropsychological functioning in diabetic children. J Clin Exp Neuropsychol 12: 613-626

7. Goldgewicht C, Slama G, Papoz L, Tchobroutsky G (1983) Hypoglycaemic reactions in 172 type 1 (insulin dependent) diabetic patients. Diabetologia 24: 95-99

8. Arias P, Kerner W, Zier H, Navascues I, Pfeiffer EF (1985) Incidence of hypoglycaemic episodes in diabetic patients under continuous subcutaneous insulin infusion and intensified conventional insulin treatment: assessment by means of semiambulatory 24-hour continuous blood glucose monitoring. Diabetes Care 8: 134-140

9. Hepburn DA, Patrick AW, Eadington DW, Ewing DJ, Frier BM (1990) Unawareness of hypoglycaemia in insulintreated diabetic patients: prevalence and relationship to autonomic neuropathy. Diabetic Med 7: 711-717

10. Pramming S, Thorsteinsson B, Bendtson I, Binder C (1990) Symptomatic hypoglycaemia in 411 type 1 diabetic patients. Diabetic Med 8: 217-222

11. Barkai L, Madácsy L (1995) Cardiovascular autonomic dysfunction in diabetes mellitus. Arch Dis Child 73: 515-518

12. Davis EA, Keating B, Byrne GC, Russell M, Jones TW (1997) Hypoglycemia: incidence and clinical predictors in a large population-based sample of children and adolescents with IDDM. Diabetes Care 20: 22-25

13. Gold AE, MacLeod KM, Frier BM (1994) Frequency of severe hypoglycaemia in patients with Type 1 diabetes with impaired awareness of hypoglycaemia. Diabetes Care 17: 697-703

14. Amiel SA, Simonson, DC, Sherwin RS, Lauritano AA, Tamborlane WV (1987) Exaggerated epinephrine responses to hypoglycemia in normal and insulin-dependent diabetic children. J Pediatr 110: 832-837

15. Jones TW, Boulware SD, Kraemer DT, Caprio S, Sherwin RS, Tamborlane WV (1991) Independent effects of youth and poor diabetes control on responses to hypoglycemia in children. Diabetes 40: 358-363

16. McCrimmon RJ, Gold AE, Deary IJ, Kelnar CJH, Frier BM (1995) Symptoms of hypoglycaemia in children with IDDM. Diabetes Care 18: 858-861

17. Maddock SJ, Trimble HC (1928) Prolonged insulin hypoglycaemia without symptoms. JAMA 91: 616-621

18. Clarke WL, Gonder-Frederick LA, Richards FE, Cryer PE (1991) Multifactorial origin of hypoglycaemic symptom awareness in IDDM. Association with defective glucose counterregulation and better glycaemic control. Diabetes 40: 680-685

19. Caspari AF, Ewing LD (1995) Severe hypoglycaemia in diabetic patients: frequency, causes, prevention. Diabetes Care 8: 141-145
20. Diabetes Control and Complications Research Group (1991) Epidemiology of severe hypoglycaemia in the Diabetes Control and Complications Trial. Am J Med 90: $450-459$

21. Hoeldtke RD, Boden G (1994) Epinephrine secretion, hypoglycaemia unawareness, and diabetic autonomic neuropathy. Ann Intern Med 120: 512-515

22. Barkai L, Madácsy L, Vámosi I (1991) Autonomic dysfunction and severe hypoglycaemia in insulin dependent diabetes mellitus. Arch Dis Child 66: 1438-1441

23. Stephenson JM, Kempler P, Cavallo Perin P, Fuller JH (1996) Is autonomic neuropathy a risk factor for severe hypoglycaemia? The EURODIAB IDDM Complications Study. Diabetologia 39: 1372-1376

24. Berlin I, Grimaldi A, Landualt C et al. (1988) Lack of hypoglycemic symptoms and decreased $\beta$-adrenergic sensitivity in insulin-dependent diabetic patients. J Clin Endocrinol Metab 66: 273-278

25. Cryer PE (1985) Does central nervous system adaptation to antecedent glycemia occur in patients with insulin dependent diabetes mellitus? Ann Intern Med 103: 284-286

26. Amiel S (1997) Hypoglycaemia in diabetes mellitus - protecting the brain. Diabetologia 40:S62-S68

27. Heller SR, Cryer PE (1991) Reduced neuroendocrine and symptomatic responses to subsequent hypoglycaemia after 1 episode of hypoglycaemia in nondiabetic humans. Diabetes 40: 223-226

28. Amiel SA, Sherwin RS, Simonson DC, Tamborlane WV (1998) Effect of intensive insulin therapy on glycaemic thresholds for counterregulatory hormone release. Diabetes 37: 901-907

29. Boyle PJ (1997) Alteration in brain glucose metabolism induced by hypoglycaemia in man. Diabetologia 40:S69-S74

30. Fanelli CG, Epifano L, Rambotti AM et al. (1993) Meticulous prevention of hypoglycaemia normalizes glycaemic thresholds and magnitude of most of the neuroendocrine responses to, and symptoms of, and cognitive function during hypoglycaemia in intensively-treated patients with short-term IDDM. Diabetes 42: 1683-1689

31. Cranston I, Lomas J, Maran A, Macdonald IA, Amiel SA (1994) Restoration of hypoglycaemia awareness in patients with long-standing insulin dependent diabetes. Lancet 44: 283-287

32. Aman J, Karlsson J, Wranne L (1989) Symptomatic hypoglycaemia in childhood diabetes: a population based questionnaire study. Diabetic Med 6: 257-261

33. Clarke WL, Gonder-Frederick L, Cox DJ (1996) The frequency of severe hypoglycaemia in children with insulindependent diabetes mellitus. Horm Res 45[suppl 1]:48-52

34. Langhan SJ, Deary IJ, Hepburn DA, Frier BM (1991) Cumulative cognitive impairment following recurrent hypoglycaemia in adult patients. Diabetologia 34: 337-344

35. Beregszászi M, Tubiana -Rufi N, Benali K, Noel M, Bloch J, Czernichow P (1997) Nocturnal hypoglycaemia in children and adolescents with insulin-dependent diabetes mellitus: prevalence and risk factors. J Pediatr 131: 27-33

36. American Diabetes Association (Position Statement) (1993) Implications of the Diabetes Control and Complications Trial. Diabetes 42: 1555-1558

37. Shield JPH, Baum JD (1994) Prevention of long term complications in diabetes. Arch Dis Child 70: 258-259 